\title{
The effect of Fe-dopant concentration on ethanol gas sensing properties of Fe doped $\mathrm{ZnO} / \mathrm{ZnO}$ shell/core nanorods
}

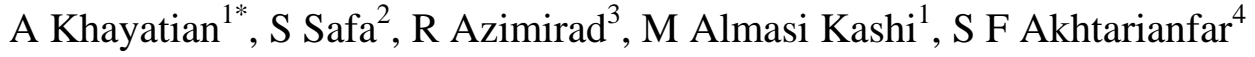 \\ ${ }^{1}$ Department of Physics, University of Kashan, Kashan, Iran \\ ${ }^{2}$ Young Researchers and Elite Club, South Tehran Branch, Islamic Azad University, Tehran, Iran \\ ${ }^{3}$ Malek-Ashtar University of Technology, Tehran, Iran \\ ${ }^{4}$ Department of Nanotechnology, University of Kashan, Kashan, Iran
}

${ }^{*}$ Corresponding author: khayatian@Kashanu.ac.ir 


\begin{abstract}
In this paper, $\mathrm{Fe}$ doped- $\mathrm{ZnO} / \mathrm{ZnO}$ shell/core nanostructures were synthesized through a simple two-step method and the effects of Fe dopant concentrations (between 0-9 at.\%) on the structural, optical, electrical and gas sensing properties were investigated. The X-ray diffraction analysis revealed that all of the samples are crystallized in the same wurtzite hexagonal crystal structure with (002) peak as the main orientation. Nevertheless, the morphology of shell/core nanorods remained stable with increasing of Fe dopant, but the crystallinity improved. The Ultraviolet -Visible spectroscopy analysis showed that the Fe ions have coordination number of $3+$ in the $\mathrm{ZnO}$ shell layer. The participation of $\mathrm{Fe}^{3+}$ ions into $\mathrm{ZnO}$ layer was also confirmed by Current-Voltage (I-V) curves where the resistance of nanorods was reduced with $\mathrm{Fe}$ concentration. Moreover, the ethanol-sensing properties of the Fe-doped $\mathrm{ZnO} / \mathrm{ZnO}$ shell/core nanorod sensors were systematically investigated. According to the results, optimum gas sensing was obtained by the addition of 0.5 at.\% $\mathrm{Fe}$ to $\mathrm{ZnO}$ shell layer which lead to significant enhancement in ethanol gas response.
\end{abstract}

Keywords: Zinc oxide nanorods; Encapsulation; Fe dopant; gas sensor; response. 


\section{Introduction}

Ethanol is a hypnotic gas which has been widely utilized in the chemical, biomedical and food industries [1]. It has been proven that long-term exposure to potentially fast volatile alcohol vapor may cause carcinogenic and mutagenic injuries on human [1]. Therefore, there is a great demand for the monitoring of ethanol vapor at trace levels.

In the recent years, different metal oxide semiconductor (MOS) nanostructures such as $\mathrm{SnO}_{2}$, $\mathrm{ZnO}, \mathrm{WO}_{3}[2-4]$ are extensively investigated for ethanol vapor sensing aims. The function of MOS chemoresistive gas sensors is based on the physical absorption of trace species (with redox interactions) on the surface states and subsequent changes in their surface electron density and conductivity [5]. Among various MOSs, $\mathrm{ZnO}$ nanostructures are the most important candidates because of their preparation simplicity, low cost, thermal and chemical stability, high electron mobility and exquisite response to several gases or volatile organic compounds [6-8].

Up to now, a various kinds of $\mathrm{ZnO}$ nanostructures including nanoflowers [9], nanorods [10], nanofibers [11], nanobelts [12], and nanotubes [13] have been prepared by various physical and chemical methods. Among these, $\mathrm{ZnO}$ nanorods are particularly useful due to their large active surface area and persistent against aggregation. Moreover, nanorods with high aspect ratio and size confinement in two coordinates demonstrate better crystallinity, higher integration density, lower power consumption and consequently the highest compatibility with microelectronic processing industries [14]. In addition, they show superior gas sensing properties because of their large active surface area and small diameter comparable with Debye length (a measure of field penetration into the bulk) [14]. Recently, one-dimensional heterostructured nanorods have attracted a great deal of attentions in the fabrication of nanodevices ranging from (opto-) 
electronic devices to chemical sensors due to their high specific surface area and special physicochemical properties [15-17]. Until now, several $\mathrm{ZnO}$ heterostructure nanorods have been developed in configuration of metal decorated nanorods for their surface functionalization, such as $\mathrm{Ag}$, $\mathrm{Pt}$ and $\mathrm{Au}$ particles [18,19], as well as $\mathrm{ZnO}$ core-shell nanostructures, such as $\mathrm{ZnO} / \mathrm{TiO}_{2}$ [20], $\mathrm{ZnO} / \mathrm{In}_{2} \mathrm{O}_{3}$ [21], and $\mathrm{SnO}_{2} / \mathrm{ZnO}$ [22]. It is confirmed that one-dimensional heterostructured nanomaterials are the best candidates for high-performance gas sensors, exhibiting high sensitivity, good selectivity, fast response and recovery times, and long-term stability [23,24]. Recently, Li et al. [25] synthesized the hollow $\mathrm{SnO}_{2}-\mathrm{ZnO}$ core-shell nanofibers for improving ethanol sensing performance and observed that the response of the sensor increased about 11 times in comparison with $\mathrm{SnO}_{2}$ sensor. Hwang et al. [26] reported a considerable improvement in gas response to both $\mathrm{NO}_{2}$ gas and ethanol vapor for $\mathrm{ZnO}-\mathrm{SnO}_{2}$ core-shell nanowires in comparison with bare $\mathrm{ZnO}$ nanorods. Choi et al. [27] investigated the effect of $\mathrm{ZnO}$ shell thickness in $\mathrm{SnO}_{2}-\mathrm{ZnO}$ core-shell nanowires on detection of trace amounts of reducing gases. Also, $\mathrm{ZnO} / \mathrm{WO}_{3}$ core/shell nanowires were synthesized by Park et al. [28] through thermal evaporation followed by sputter-deposition of $\mathrm{WO}_{3}$ and their sensing properties toward $\mathrm{H}_{2}$ gas were examined.

Since the sensing mechanism of $\mathrm{ZnO}$ nanorods is based on the surface reaction with the exposed gas (adsorption and desorption of the test gas molecules), surface decoration of nanoparticles or doping with an element that has a stronger chemical affinity may cause enhancement of gas sensing performance [29-31]. Usually, doping in nanostructures can create defects and these defects play a role as preferential adsorption sites for adsorption of gas molecules [32]. However, the results of many publications showed that direct doping of multivalent ions like In, $\mathrm{Al}, \mathrm{Sn}$ and etc. with desired high amounts is a challenging issue [33-36]. 
Fe doped $\mathrm{ZnO}$ nanostructures have fantastic characterization so that up to now, the many groups have been investigated their properties and applications. Fe ions have multivalence state. It was reported that $\mathrm{Fe}$ dopant into the $\mathrm{ZnO}$ appears in the form of $\mathrm{Fe}^{2+}$ and $\mathrm{Fe}^{3+}$ which influenced the band gap and electrical property [37,38]. In this work, we have suggested the fabrication of Fe doped $\mathrm{ZnO} / \mathrm{ZnO}$ shell/core nanorods (NRs) using a simple and low cost hydrothermal method followed by dip. The effect of Fe content on structural, optical, electrical and also gas sensing properties to ethanol were investigated in detail. In addition, we have also done a complementary work to find out the optimal Fe concentration in shell layer.

\section{Material and methods}

\subsection{Sample preparation}

The Fe doped- $\mathrm{ZnO} / \mathrm{ZnO}$ shell/core NRs were prepared on glass substrates by a simple two-step method, as reported elsewhere [23]. Firstly, the glass substrates were ultrasonically cleaned by acetone, ethanol and deionized water to remove contaminants. Then, the clean glass substrates were spin-coated by a sol of $0.05 \mathrm{M}$ zinc acetate dihydrate $\left(\mathrm{Zn}\left(\mathrm{NO}_{3}\right)_{2}, 2 \mathrm{H}_{2} \mathrm{O}\right.$, Merck, 99.0\%) and $0.06 \mathrm{M}$ diethanolamine $\left(\mathrm{C}_{4} \mathrm{H}_{11} \mathrm{NO}_{2}\right.$, Merck, 98\%) in ethanol. The spin-coating was performed with a speed of $3000 \mathrm{rpm}$ for $30 \mathrm{~s}$ and then, the obtained films were dried at $180^{\circ} \mathrm{C}$ for $10 \mathrm{~min}$. This procedure was repeated for five times and finally, the films were annealed at $450^{\circ} \mathrm{C}$ for $1 \mathrm{~h}$ in air.

In the second step, the hydrothermal method was used to grow up the oriented ZnO NR array on $\mathrm{ZnO}$ seeds. The substrates were suspended horizontally in a $0.001 \mathrm{M}$ zinc nitrate and $0.1 \mathrm{M}$ sodium hydroxide aqueous solution under slow constant stirring at $70^{\circ} \mathrm{C}$ for $90 \mathrm{~min}$. Afterwards, the samples were cleaned by deionized water to remove the residual salts, dried in air and finally annealed at $500^{\circ} \mathrm{C}$ for $1 \mathrm{~h}$. 
The shell layer was formed by encapsulation $\mathrm{ZnO}$ NRs by using dip-coating method in a Fedoped sols including $0.5 \mathrm{M}$ zinc acetate dihydrate, $0.6 \mathrm{M}$ diethanolamine and various concentrations of iron nitrate hexahydrate $\left(\mathrm{Fe}\left(\mathrm{NO}_{3}\right)_{2}, 6 \mathrm{H}_{2} \mathrm{O}\right.$, Merck, $\left.98 \%\right)([\mathrm{Fe} / \mathrm{Zn}]=0,0.5,1.5$, 4.5 and 9 at.\%) dissolved in ethanol. To obtain a transparent and homogeneous solution, each sol was stirred at $60^{\circ} \mathrm{C}$ for $20 \mathrm{~min}$. Then, the annealed $\mathrm{ZnO}$ NR samples were dipped vertically into the solution and withdrawn for $1 \mathrm{~min}$. Subsequently, they were pulled out at a constant speed of $3 \mathrm{~cm} / \mathrm{min}$ and dried at $180^{\circ} \mathrm{C}$ for $10 \mathrm{~min}$ in air. The $\mathrm{ZnO}$ shell/core NRs with uniform layer with desired thickness were obtained by two dipping cycles. Finally, all of the samples were annealed at $450^{\circ} \mathrm{C}$ for $1 \mathrm{~h}$ in air. The sensors were formed by sputtering of Au grid contacts $(70 \mathrm{~nm})$ on top of the samples in metal-semiconductor-metal structure.

\subsection{Characterizations}

The X-ray diffraction (XRD) (X'Pert PRO, Philips) was used for structural investigation. Topography of the samples was investigated by scanning electron microscope (SEM) (VEGA, TESCAN) and atomic force microscope (AFM) (NT-MDT). The SEM samples had been coated by a gold thin film using a desktop sputtering system (Nanostructured Coating Co.-Iran). The optical properties of the prepared samples were measured using an ultraviolet -visible (UV-Vis) spectrophotometer (Jasco v570). A two point probe method was applied for verifying the electrical resistivity of the films. The performance of the sensors to ethanol vapor was measured by using a purpose-built system. The sensor response is defined by the ratio $R_{a} / R_{g}$ while $R_{a}$ and $\mathrm{R}_{\mathrm{g}}$ are the sensor electrical resistance in air and gas, respectively.

\section{Results and discussion}

The AFM micrograph of seed layer as well as SEM images of bare ZnO NRs and 1.5 at.\% Fe doped- $\mathrm{ZnO} / \mathrm{ZnO}$ shell/core NRs are shown in Fig. 1(a-c), respectively. Fig. 1(b) contains $\mathrm{ZnO}$ 
NRs with diameter of $40 \sim 60 \mathrm{~nm}$ while the encapsulated nanorods have been thickened to about 60-100 nm (Fig. 1(c)). The length $(\sim 1 \mu \mathrm{m})$ and number density $\left(\sim 3 \times 10^{7} \mathrm{~cm}^{-2}\right)$ of the NRs were almost unchanged by encapsulation. So, it indicates that the encapsulation process forms a thin shell layer on the surface of $\mathrm{ZnO}$ NRs whereas the length of NRs is nearly intact. These results demonstrate that the encapsulation of $\mathrm{ZnO} \mathrm{NRs}$ is a well-controllable efficient method for fabrication of doped $\mathrm{ZnO}$ NRs with minimal morphological changes. Also, it has been reported that the surface of the $\mathrm{ZnO}$ NRs would be partially roughens after encapsulation $[39,40]$ which is an important issue for surface adsorption and desorption of the oxygen atoms.

<Fig. 1>

The XRD patterns of $x$ at.\% Fe doped-ZnO/ZnO shell/core NRs $(0 \leq x \leq 9)$ are shown in Fig. 2(a). As can be seen, all of the patterns have a main diffraction peak at $\sim 34^{\circ}$ corresponding to (002) plane of $\mathrm{ZnO}$ NRs which indicates a preferential texture in hexagonal wurtzite crystal structure (JCPDS Card No. 80-0074). There are no other diffraction peaks corresponding to $\mathrm{FeO}, \mathrm{Fe}_{2} \mathrm{O}_{3}$ or $\mathrm{Fe}_{3} \mathrm{O}_{4}$ phases indicating that $\mathrm{Fe}$ atoms are doped in the $\mathrm{ZnO}$ host lattice without any segregation [41].

<Fig. 2>

The intensity of (002) peak considerably increases with incorporation of Fe atoms (up to 4.5 at.\%) in the shell layer. In order to quantitatively evaluate the preferential crystal orientation, the texture coefficient parameter (TC) for the (002) peak of ZnO NRs was calculated and plotted in the inset of Fig. 2(a) [42]:

$$
T C(h k l)=\frac{I(h k l) / I_{0}(h k l)}{(1 / n) \sum_{n} I(h k l) / I_{0}(h k l)}
$$


where $I(h k l)$ is the intensity of the $(h k l)$ plane, $I_{0}(h k l)$ is the relative intensity of the corresponding plane given in the XRD reference (JCPDS Card No. 80-0074), and $\mathrm{n}$ is the total number of diffraction peaks. When the $T C$ value is more than 1 , the preferential growth can be assumed. The texture coefficient for (002) peak increases with the increase of Fe concentration up to 4.5 at. $\%$ and then decreases slightly. This observation indicates that 4.5 at. $\%$ Fe doped $\mathrm{ZnO}$ NRs can be taken into account as the optimized value for improving the crystallinity of shell layer. Similar observations have been reported by others [41,43]. For example, Xu et al. [41] showed that the 1 at.\% Fe-doped $\mathrm{ZnO}$ thin film has the strongest (002) peak while higher concentrations of $\mathrm{Fe}$ gradually decline the preferential growth of (002).

The $d$-spacing value of (002) peak and average grain size, $D$, were calculated for all of the $\mathrm{ZnO}$ NRs (Fig. 2(b)). The decrease of the $d$-spacing value with increasing Fe dopant content can be attributed to the difference in ionic radius between $\mathrm{Zn}$ and $\mathrm{Fe}$ ions [40]. It is known that Fe ions can be substituted in the $\mathrm{Zn}$ sites in the $\mathrm{ZnO}$ lattice in both $\mathrm{Fe}^{2+}$ and $\mathrm{Fe}^{3+}$ states $[37,44,45]$. The X-ray patterns show that the (002) peak of Fe doped ZnO NRs shifted toward the higher angles. Thus, according to the ionic radius of $\mathrm{Zn}$ and $\mathrm{Fe}\left(\mathrm{Fe}^{2+} \sim 0.76 \AA, \mathrm{Fe}^{3+} \sim 0.64 \AA\right.$ and $\mathrm{Zn}^{2+} \sim 0.74 \AA$ [45]) and also contraction of $\mathrm{ZnO}$ lattice (by increasing the Fe content), it can be discerned that the $\mathrm{Fe}^{+3}$ ionic state is predominantly substituted instead of $\mathrm{Zn}^{2+}$ ions in the $\mathrm{ZnO}$ lattice.

The transmittance spectra of the core/shell NRs are shown in figure 3(a). As can be seen, the transmittance in the visible range increase with Fe doped into $\mathrm{ZnO}$ shell layer upto 4.5 at.\%. Also, it is clear that absorption edge of all NRs samples is sharp and located at wavelengths below $400 \mathrm{~nm}$. This implies the intrinsic absorption edge is originated from direct transition of electrons and then all the films are assigned to be semiconductors with a direct band gap [46]. The transmittance increasing can be described as the enhancement of the crystallinity of shell 
layer with Fe doped, as seen in the structural analysis. The optical band gap of samples was obtained by exerting the Tauc relation to optical transmittance spectra. The optical band gap is determined through the plotting a direct line at absorption edge of the curve in $(\alpha h v)^{p}$ versus $h v$ plot. The $h v$ is the photon energy, $A$ is the constant of the transmittance probability, $E_{g}$ is the value of band gap, and $p$ is a power constant which takes the value of 2 for direct transition and $1 / 2$ for indirect transition. The results of fittings showed that all of the Fe doped-ZnO NRs behave like a direct transition semiconductor. The value of the optical band gap of the samples was obtained through extrapolating the linear part of the graph at $(\alpha h v)^{2}=0$ (Fig. 3). The band gap of pure $\mathrm{ZnO} / \mathrm{ZnO}$ shell/core $\mathrm{NRs}$ is $3.11 \mathrm{eV}$ which is regularly increased with increasing the concentration of Fe dopant to about $3.28 \mathrm{eV}$ for 9 at.\% Fe doped $\mathrm{ZnO}$ NRs. The enhancement of the optical band gap of Fe doped $\mathrm{ZnO}$ NRs may be explained by Burstein-Moss band filling effect [41]. The $\mathrm{ZnO}$ is an $\mathrm{n}$-type semiconductor and the Fermi level $\left(\xi_{\mathrm{n}}\right)$ positions inside of the band gap. According to the Burstein-Moss effect, if the Fermi level gets pushed inside of the conduction band, therefore the states below $\xi_{\mathrm{n}}$ in the conduction band are filled and the absorption edge shifts to the higher energy caused to widening the band gap. This is satisfied when $\mathrm{Fe}$ ions contribute to coordination number $3+$ in the $\mathrm{ZnO}$ structure [47].

<Fig. 3>

The electrical resistivity of samples was measured through 2-electrode method and compared as shown in Fig. 4. Also, the inset of Fig. 4 shows that all of the bare and doped ZnO NRs follow from ohmic behavior in the applied DC voltage range of 0-6 V. By comparing the results, it was found that the resistance of devices remarkably reduces with increasing Fe concentration into $\mathrm{ZnO}$ shell layer up to 4.5 at.\% Fe, and then, it increases a little in 9 at.\% Fe doped sample, which confirms the ionic state of $\mathrm{Fe}$ dopant $\left(\mathrm{Fe}^{3+}\right)$ obtained by XRD results. 
$<$ Fig. 4>

In other words, $\mathrm{ZnO}$ is naturally an n-type semiconductor due to its intrinsic defect states such as zinc interstitials and oxygen vacancies [48]. Besides, $\mathrm{ZnO}$ surface tends to intrinsically adsorb the oxygen molecules which act as electron acceptors. The adsorbed oxygen species capture electrons from the conduction band of the $\mathrm{ZnO}$ and form chemisorbed $\mathrm{O}_{2}^{-}$or $\mathrm{O}_{2}{ }^{2-}$ [49]. This leads to surface electron depletion in the $\mathrm{ZnO}$ semiconductor and consequently, decreases of the carrier density. As can be seen in Fig. 4, the resistance of Fe-doped ZnO NRs decreases with the increase of $\mathrm{Fe}$ concentration in shell layer. Therefore, one can conclude that much of the multivalent $\mathrm{Fe}$ atoms $(2+$ and $3+)$ are substituted in $\mathrm{ZnO}$ lattice in three valence state $\left(\mathrm{Fe}^{3+}\right)$. The $\mathrm{Fe}^{3+}$ ions substituted into $\mathrm{Zn}^{2+}$ lattice sites act as donor dopants and increase the carrier concentration and thereby, electrical conductivity [41]. On the other hand, increasing the concentration of Fe dopant increases the scattering centers [50] and consequently, impedes the mobility of electronic carriers, as what is seen for the sample with 9 at.\% Fe dopant.

In the next step, the performance of pure and Fe-doped $\mathrm{ZnO} / \mathrm{ZnO}$ shell/core $\mathrm{NR}$ sensors to ethanol vapor at various temperatures (room temperature to $270^{\circ} \mathrm{C}$ ) was investigated. Fig. 5 shows the response of the samples to $500 \mathrm{ppm}$ ethanol vapor at different operating temperatures. The optimal operating temperature was $230^{\circ} \mathrm{C}$ for bare $\mathrm{ZnO} / \mathrm{ZnO}$ sample and $250^{\circ} \mathrm{C}$ for $\mathrm{Fe}$ doped NR sensors. It is clear that the optimal operating temperature depends to the Fe dopant. Fig. 6 shows the response of the samples to different concentrations of ethanol at the optimized temperatures.

$<$ Fig. 5>

<Fig. 6> 
For studying the current levels of the sensors, the changes of current versus time to the single ethanol cycle $(500 \mathrm{ppm})$ at their optimal operating temperatures is shown in Fig 7 (a). The current level for the pure $\mathrm{ZnO}$ and $4.5 \% \mathrm{Fe}$ doped sensors are minimum and maximum, respectively. The highest electrical current level of the $4.5 \%$ Fe doped sample is due to the increase of charge carriers in this sensor which was previously described. A higher electrical current level is important for making a device that not only operates with simple electrical measuring tools, but also is less sensitive to environmental noises.

For the better comparison of the sensors response, the each current curve of Fig. 7(a) was normalized to its base current $\left(\mathrm{I}_{0}\right)$ as the normalized response curve (Fig. 7(b)) [23]. It can be seen that the sample with $0.5 \%$ Fe dopant shows the maximum response (18.6) while the sensor with 4.5 at.\% Fe encapsulated $\mathrm{ZnO}$ nanorods shows the minimum response (2.2).

\section{<Fig. 7>}

Mechanism of ethanol sensing by ZnO NRs has been described by many groups [25,51]. In the sensing process and at the optimal operating temperature, the oxygen molecules adsorbed on the surface of $\mathrm{ZnO}$ NRs and afterwards, dissociated to atomic oxygen [3]. These species capture the surface electrons from the conduction band of $\mathrm{ZnO}$, chemisorb on the surface and produce different species of oxygen $\left(\mathrm{O}^{2-}, \mathrm{O}^{-}, \mathrm{O}_{2}{ }^{-}\right)$. Therefore, an electron depletion layer on the surface of $\mathrm{ZnO}$ would be formed. The formation of the depletion layer increases the electrical resistance of the sensing layer. When $\mathrm{ZnO}$ NRs are exposed to the ethanol vapor, the reaction between ethanol and ionic oxygen goes on as following:

$$
\mathrm{CH}_{3} \mathrm{CH}_{2} \mathrm{OH}_{\mathrm{ads}}+6 \mathrm{O}_{\mathrm{ads}}{ }^{-} \rightarrow 2 \mathrm{CO}_{2}+3 \mathrm{H}_{2} \mathrm{O}+6 \mathrm{e}^{-}
$$


According to the above chemical reaction, the freed electrons tend to rapidly return back to the conduction band of NRs. Hence, the resistance of the $\mathrm{ZnO}$ NRs decreases in the presence of ethanol and sensor current increases.

The performance of $\mathrm{ZnO}$ NRs-based gas sensors is dependent to parameters like dopant material and quality of surface depletion layer. Hongsith et al. [52] offered a formula for explaining the ethanol sensing response of a semiconducting sensor which contains the effect of different parameters:

$$
S_{g}=\frac{R_{a}}{R_{g}}=\frac{\Gamma_{t} k_{E t h}(\mathrm{~T})\left[\mathrm{O}_{a d s}^{i o n}\right]^{b}\left[\mathrm{CH}_{3} \mathrm{CH}_{2} \mathrm{OH}\right]^{b}}{n_{0}}+1
$$

where $\Gamma_{t}$ is a time constant, $k_{E t h}(T)$ reaction rate constant as a function of activation energy and temperature, $\mathrm{b}$ is the charge parameter which is 1 and 0.5 for $\mathrm{O}^{-}$and $\mathrm{O}^{2-}$, respectively. [ $\mathrm{O}_{\text {ads }}$ ] and $\left[\mathrm{CH}_{3} \mathrm{CH}_{2} \mathrm{OH}\right]$ are concentrations of adsorbed oxygen on the surface of metal oxide sensor and ethanol vapor, respectively. Also, $n_{0}$ is the concentration of free electrons at the working temperature and air atmosphere which determines the conductivity and base current of the sensor at the operating temperature. However, according to this equation response of the sensor is proportional to the reaction rate.

As seen, there is an optimum operating temperature for each sensor in which response is highest and above that, the response decreases. It results that $\mathrm{ZnO}$ NRs sensors should be operated in optimum temperature for enhancement of activation and chemisorption of ethanol species by the oxygen species [53]. As the thermal energy reaches the proper limit to conquer the activation energy barrier of reaction, electron concentration significantly increases and a high response is accomplished [54]. Increasing temperature above the optimum value causes to intensive 
desorption of oxygen molecules from the surface of $\mathrm{ZnO}$ NRs and consequently reduction of the sensor response due to progressive desorption of oxygen ionic species [53,55].

In accordance with above equation, the increasing of responsivity of 0.5 at.\% Fe doped$\mathrm{ZnO} / \mathrm{ZnO}$ shell/core NRs can be well-described. Here, surface doping of $\mathrm{ZnO}$ with the Fe ions increases the surface reaction rate. This implies that Fe ions injected to the surface of $\mathrm{ZnO}$ NRs operate as a catalyst and subsequently, enhance the reaction rate and adsorption of gas species (oxygen and target gas) on the surface of crystal at the optimum temperature. Since sensing quality of metal oxide sensors is highly affected by adsorption and desorption of gas species on the surface, the sensor response increases in 0.5 at.\% $\mathrm{Fe}$ doped- $\mathrm{ZnO} / \mathrm{ZnO}$ shell/core NRs. According to space-charge model, adsorption of oxygen on the oxide surface make the depletion layer thicker and this property can improve the sensing features of 0.5 at. $\% \mathrm{Fe}$ doped- $\mathrm{ZnO} / \mathrm{ZnO}$ shell/core NRs [41].

The activation energy of the sensors can be calculated by the Arrhenius equation [56].

$k_{E t h}(T)=A \exp \left(-\frac{E_{a}}{k_{B} T}\right)$

where $E_{a}$ is activation energy. According to this equation, increase of the sensor temperature amplifies the reaction rate. On the other hand, Fe dopant could increase the activation energy for the $\mathrm{Zn}$ oxide nanostructures [57]. Therefore, it is clear that adding of Fe dopant into shell layer leads to increase the optimum temperature from $230^{\circ} \mathrm{C}$ for pure $\mathrm{ZnO} / \mathrm{ZnO}$ shell/core $\mathrm{NRs}$ to $250^{\circ} \mathrm{C}$ for $\mathrm{Fe}$ doped- $\mathrm{ZnO} / \mathrm{ZnO}$ shell/core NRs.

On the other hand, further increasing the number of $\mathrm{Fe}$ ions in the $\mathrm{ZnO}$ shell layer have a destructive effect on the ethanol sensing. This leads to the enhancement of the number of carriers, which can decrease the response of the sensors (especially $4.5 \% \mathrm{Fe}$ doped- $\mathrm{ZnO} / \mathrm{ZnO}$ 
shell/core NRs) according to the equation (1). Furthermore, large number of scattering atoms for the high concentrations of $\mathrm{Fe}$ decreases the surface reaction rate in the shell layer and declines the oxygen capturing sites. This can cause to reduce the Debye length and consequently attenuation of depletion region.

Using Fe dopant for modification of sensing properties of zinc oxide and other semiconductors have been reported by different groups. Kuo et al. [58] investigated the response of $\mathrm{ZnO}$ thin films doped with $\mathrm{Fe}$ for ethanol sensing and founded the maximum response for 5\% doping. Yuliarto et al. [59] measured the response of Fe doped thin film-based sensors towards liquefied petroleum gas and observed the maximum response for the sample with $0.5 \% \mathrm{Fe}$. In addition, the effective catalyst role of $\mathrm{Fe}$ in improvement of $\mathrm{H}_{2} \mathrm{~S}$ gas detective properties in sensors fabricated based on the $\mathrm{SnO}_{2}$ nanostructures has also been reported [60].

\section{Conclusions}

In summary, the pure and $\mathrm{Fe}$ doped- $\mathrm{ZnO} / \mathrm{ZnO}$ NRs samples were prepared by a simple two-steps process. The XRD characterization showed that all of the NRs were crystallized in the wurtzite hexagonal crystal structure. According to the SEM images, one dimensional $\mathrm{ZnO}$ nanorods were grown in hydrothermal method and appropriately encapsulated with a thin layer of Fe-doped $\mathrm{ZnO}$. With increase in Fe dopant concentration into $\mathrm{ZnO}$ shell layer, the band gap increased from $3.11 \mathrm{eV}$ to $3.27 \mathrm{eV}$. The I-V measurements showed that the electrical resistance of samples decrease with increase Fe concentration can easily. The sensors exhibited a good performance in detecting the ethanol vapor. Addition of Fe-dopant into shell layer increased the responsivity of the sensors compared to pure $\mathrm{ZnO}$ sample and was also optimized at dopant concentration amount of 0.5 at $\%$. 


\section{Acknowledgment}

Authors would like to thank the Iran National Science Foundation for the financial support of the work. Also, authors are grateful to the University of Kashan for supporting this work by Grant No $(159023 / 60)$.

\section{References}

[1] A. Mhamdi, A. Labidi, B. Souissi, M. Kahlaoui, A. Yumak, K. Boubaker, A. Amlouk, M. Amlouk, Impedance spectroscopy and sensors under ethanol vapors application of sprayed vanadium-doped ZnO compounds, J. Alloys Compd. 639 (2015) 648-658.

[2] P. Sun, C. Wang, J. Liu, X. Zhou, X. Li, X. Hu, G. Lu, Hierarchical assembly of $\alpha-\mathrm{Fe}_{2} \mathrm{O}_{3}$ nanosheets on $\mathrm{SnO}_{2}$ hollow nanospheres with enhanced ethanol sensing properties, ACS Appl. Mater. interfaces 7(34) (2015) 19119-19125.

[3] S. Safa, R. Azimirad, Kh. Mohammadi, R. Hejazi, A. Khayatian, Investigation of ethanol vapor sensing properties of $\mathrm{ZnO}$ flower-like nanostructures, Measurement 73 (2015) 588-595.

[4] W. Zeng, B. Miao, T. Li, H. Zhang, S. Hussain, Y. Li, W. Yu, Hydrothermal synthesis, characterization of $\mathrm{h}-\mathrm{WO}_{3}$ nanowires and gas sensing of thin film sensor based on this powder, Thin Solid Films 584 (2015) 294-299.

[5] P.V. Bakharev, D.N. McIlroy, Signal-to-noise enhancement of a nanospring redox-based sensor by lock-in amplification, Sensors 15(6) (2015) 13110-13120.

[6] S. Ranwa, M. Kumar, J. Singh, M. Fanetti, M. Kumar, Schottky-contacted vertically selfaligned $\mathrm{ZnO}$ nanorods for hydrogen gas nanosensor applications, J. Appl. Phys. 118(3) (2015) 034509. 
[7] K. Diao, M. Zhou, J. Zhang, Y. Tang, S. Wang, X. Cui, High response to $\mathrm{H}_{2} \mathrm{~S}$ gas with facile synthesized hierarchical ZnO microstructures, Sens. Actuators, B 219 (2015) 30-37.

[8] E. Şennik, S. Kerli, Ü. Alver, Z.Z. Öztürk, Effect of fluorine doping on the $\mathrm{NO}_{2}$ sensing properties of ZnO thin films, Sens. Actuators, B 216 (2015) 49-56.

[9] Y. Zhang, T. Liu, J. Hao, L. Lin, W. Zeng, X. Peng, Z. Wang, Enhancement of $\mathrm{NH}_{3}$ sensing performance in flower-like $\mathrm{ZnO}$ nanostructures and their growth mechanism, Appl. Surf. Sci. 357 (2015) 31-6.

[10] L. Wang, Y. Kang, X. Liu, S. Zhang, W. Huang, S. Wang, ZnO nanorod gas sensor for ethanol detection, Sens. Actuators, B 162(1) (2012) 237-243.

[11] C. Lai, X. Wang, Y. Zhao, H. Fong, Z. Zhu, Effects of humidity on the ultraviolet nanosensors of aligned electrospun ZnO nanofibers, RSC Advances 3(18) (2013) 6640-6645.

[12] Z. Zhang, Q. Liao, X. Zhang, G. Zhang, P. Li, S. Lu, S. Liu, Y. Zhang, Highly efficient piezotronic strain sensors with symmetrical Schottky contacts on the monopolar surface of $\mathrm{ZnO}$ nanobelts, Nanoscale 7(5) (2015) 1796-1801.

[13] J. Yang, Y. Lin, Y. Meng, Y. Liu, A two-step route to synthesize highly oriented $\mathrm{ZnO}$ nanotube arrays, Ceram. Int. 38(6) (2012) 4555-4559.

[14] N.D. Khoang, N. Van Duy, N.D. Hoa, N. Van Hieu, Design of $\mathrm{SnO}_{2} / \mathrm{ZnO}$ hierarchical nanostructures for enhanced ethanol gas-sensing performance, Sens. Actuators, B 174 (2012) $594-601$. 
[15] H.L. Feng, W.Q. Wu, H.S. Rao, L.B. Li, D.B. Kuang, C.Y. Su, Three-dimensional hyperbranched $\mathrm{TiO}_{2} / \mathrm{ZnO}$ heterostructured arrays for efficient quantum dot-sensitized solar cells, J. Mater. Chem. A. 3(28) (2015) 14826-14832.

[16] K. Zhang, Y. Zhang, T. Zhang, W. Dong, T. Wei, Y. Sun, X. Chen, G. Shen, N. Dai, Vertically coupled $\mathrm{ZnO}$ nanorods on $\mathrm{MoS}_{2}$ monolayers with enhanced Raman and photoluminescence emission, Nano Res. 8(3) (2015) 743-50.

[17] W. Kim, M. Baek, K. Yong, Fabrication of $\mathrm{ZnO} / \mathrm{CdS}, \mathrm{ZnO} / \mathrm{CdO}$ core/shell nanorod arrays and investigation of their ethanol gas sensing properties, Sens. Actuators, B 223 (2016) 599-605.

[18] Y. Liang, N. Guo, L. Li, R. Li, G. Ji, S. Gan, Fabrication of porous 3D flower-like Ag/ZnO heterostructure composites with enhanced photocatalytic performance, Appl. Surf. Sci. 332 (2015)32-39.

[19] Z. Kang, X. Yan, Y. Wang, Y. Zhao, Z. Bai, Y. Liu, K. Zhao, S. Cao, Y. Zhang, Selfpowered photoelectrochemical biosensing platform based on Au NPs@ZnO nanorods array, Nano Res. (2015) 1-9.

[20] R. Wang, X. Xu, Y. Zhang, Z. Chang, Z. Sun, W. Dong, Functionalized ZnO@ $\mathrm{TiO}_{2}$ nanorod array film loaded with $\mathrm{ZnIn}_{0.25} \mathrm{Cu}_{0.02} \mathrm{~S}_{1.395}$ solid-solution: synthesis, characterization and enhanced visible light driven water splitting, Nanoscale 7 (2015) 11082-11092.

[21] B.R. Huang, J.C. Lin, Core-shell structure of zinc oxide/indium oxide nanorod based hydrogen sensors, Sens. Actuators, B 174 (2012) 389-393. 
[22] B. Zhang, W. Fu, H. Li, X. Fu, Y. Wang, H. Bala, G. Sun, X. Wang, Y. Wang, J. Cao, Z. Zhang, Actinomorphic $\mathrm{ZnO} / \mathrm{SnO}_{2}$ core-shell nanorods: Two-step synthesis and enhanced ethanol sensing propertied, Mater. Lett. 160 (2015) 227-230.

[23] A. Khayatian, M.A. Kashi, R. Azimirad, S. Safa, Enhanced gas-sensing properties of ZnO nanorods encapsulated in an Fe-doped ZnO shell, J. Phys. D: Appl. Phys. 47(7) (2014) 075003.

[24] D.X. Ju, H.Y. Xu, Z.W. Qiu, Z.C. Zhang, Q. Xu, J. Zhang, J.Q. Wang, B.Q. Cao, Near room temperature, fast-response, and highly sensitive triethylamine sensor assembled with Au-Loaded $\mathrm{ZnO} / \mathrm{SnO}_{2}$ core-shell nanorods on flat alumina substrates, ACS Appl. Mater. interfaces 7(34) (2015) 19163-19171.

[25] W. Li, S. Ma, Y. Li, G. Yang, Y. Mao, J. Luo, D. Gengzang, X. Xu, S. Yan, Enhanced ethanol sensing performance of hollow $\mathrm{ZnO}-\mathrm{SnO}_{2}$ core-shell nanofibers, Sens. Actuators, B 211 (2015) 392-402.

[26] I.S. Hwang, S.J. Kim, J.K. Choi, J. Choi, H. Ji, G.T. Kim, G. Cao, J.H. Lee, Synthesis and gas sensing characteristics of highly crystalline $\mathrm{ZnO}-\mathrm{SnO}_{2}$ core-shell nanowires, Sens. Actuators, B 148(2) (2010) 595-600.

[27] S.W. Choi, A. Katoch, G.J. Sun, J.H. Kim, S.H. Kim, S.S. Kim. Dual functional sensing mechanism in $\mathrm{SnO}_{2}-\mathrm{ZnO}$ core-shell nanowires, ACS Appl. Mater. interfaces 6(11) (2014) 82818287.

[28] S. Park, T. Hong, J. Jung, C. Lee, Room temperature hydrogen sensing of multiple networked $\mathrm{ZnO} / \mathrm{WO}_{3}$ core-shell nanowire sensors under UV illumination, Curr. Appl. Phys. 14(9) (2014)1171-5. 
[29] M.F. Alam, D.T. Phan, G.S. Chung, Palladium nanocubes decorated on a one-dimensional $\mathrm{ZnO}$ nanorods array for use as a hydrogen gas sensor, Mater. Lett. 156 (2015)113-117.

[30] W.H. Zhang, W.D. Zhang, J.F. Zhou, Solvent thermal synthesis and gas-sensing properties of Fe-doped ZnO, J. Mater. Sci. 45(1) (2010) 209-215.

[31] A. Yu, J. Qian, H. Pan, Y. Cui, M. Xu, L. Tu, Q. Chai, X. Zhou, Micro-lotus constructed by Fe-doped $\mathrm{ZnO}$ hierarchically porous nanosheets: preparation, characterization and gas sensing property, Sens. Actuators, B 158(1) (2011) 9-16.

[32] S.Y. Lee, Regular Paper: Sensing Properties of Ga-doped ZnO Nanowire Gas Sensor, Trans. Electr. Electron. Mater. (TEEM) 16(2) (2015) 78-81.

[33] P. Nunes, E. Fortunato, P. Tonello, F.B. Fernandes, P. Vilarinho, R. Martins, Effect of different dopant elements on the properties of $\mathrm{ZnO}$ thin films, Vacuum 64(3) (2002) 281-285.

[34] B. Huang, C. Zhao, M. Zhang, Z. Zhang, E. Xie, J. Zhou, W. Han, Doping effect of $\operatorname{In}_{2} \mathrm{O}_{3}$ on structural and ethanol-sensing characteristics of $\mathrm{ZnO}$ nanotubes fabricated by electrospinning, Appl. Surf. Sci. 349 (2015) 615-621.

[35] S.C. Navale, V. Ravi, I.S. Mulla, S.W. Gosavi, S.K. Kulkarni, Low temperature synthesis and NOx sensing properties of nanostructured Al-doped ZnO, Sens. Actuators, B 126(2) (2007) 382-386.

[36] S.I. Maximenko, L. Mazeina, Y.N. Picard, J.J. Freitas, V.M. Bermudez, S.M. Prokes, Cathodoluminescence studies of the inhomogeneities in Sn-doped $\mathrm{Ga}_{2} \mathrm{O}_{3}$ nanowires, Nano Lett. 9(9) (2009) 3245-5321. 
[37] T.N. Soitah, Y. Chunhui, S. Liang, Effect of Fe doping on structural and electrical properties of nanocrystalline $\mathrm{ZnO}$ thin films prepared by sol-gel dip coating technique, Sci. Adv. Mater. 2(4) (2010) 534-538.

[38] S. Baek, J. Song, S. Lim, Improvement of the optical properties of $\mathrm{ZnO}$ nanorods by $\mathrm{Fe}$ doping, Physica B 399(2) (2007) 101-104.

[39] S. Chatterjee, O.D. Jayakumar, A.K. Tyagi, P. Ayyub, Template-based fabrication of AgZnO core-shell nanorod arrays, J. Cryst. Growth 312(19) (2010) 2724-2728.

[40] R.C. Wang, H.Y. Lin, Simple fabrication and improved photoresponse of $\mathrm{ZnO}-\mathrm{Cu}_{2} \mathrm{O}$ coreshell heterojunction nanorod arrays, Sens. Actuators, B 149(1) (2010) 94-97.

[41] L. $\mathrm{Xu}, \mathrm{X}$. Li, Influence of Fe-doping on the structural and optical properties of $\mathrm{ZnO}$ thin films prepared by sol-gel method, J. Cryst. Growth 312(6) (2010) 851-855.

[42] H.C. Hsu, C.S. Cheng, C.C. Chang, S. Yang, C.S. Chang, W.F. Hsieh, Orientation-enhanced growth and optical properties of $\mathrm{ZnO}$ nanowires grown on porous silicon substrates, Nanotechnology 16(2) (2005) 297.

[43] J. Morales, E. Andrade, M. Miki-Yoshida, Influence of Al, In, Cu, Fe and Sn dopants in the microstructure of zinc oxide thin films obtained by spray pyrolysis, Thin Solid Films 366(1) (2000) 16-27.

[44] L.M. Wang, J.W. Liao, Z.A. Peng, J.H. Lai, Doping effects on the characteristics of Fe: ZnO films: valence transition and hopping transport, J. Electrochem. Soc. 156(2) (2009) H138142. 
[45] M.L. Dinesha, H.S. Jayanna, S. Ashoka, G.T. Chandrappa, Temperature dependent electrical conductivity of $\mathrm{Fe}$ doped $\mathrm{ZnO}$ nanoparticles prepared by solution combustion method, J. Alloys Compd. 485(1) (2009) 538-541.

[46] He Y, Zhang W, Zhang S, Kang X, Peng W, Xu Y. Study of the photoconductive ZnO UV detector based on the electrically floated nanowire array. Sens. Actuators, A, 181 (2012) 6-12.

[47] S. Singh, N. Rama, K. Sethupathi, M.R. Rao, Correlation between electrical transport, optical, and magnetic properties of transition metal ion doped ZnO, J. Appl. Phys. 103(7) (2008) $07 \mathrm{D} 108$.

[48] Z.H. Lim, Z.X. Chia, M. Kevin, A.S. Wong, G.W. Ho, A facile approach towards ZnO nanorods conductive textile for room temperature multifunctional sensors, Sens. Actuators, B 151(1) (2010) 121-126.

[49] C.Y. Lu, S.P. Chang, S.J. Chang, T.J. Hsueh, C.L. Hsu, Y.Z. Chiou, I.C. Chen, A lateral ZnO nanowire UV photodetector prepared on a $\mathrm{ZnO}$ :Ga/glass template, Semicond. Sci. Technol. 24(7) (2009) 075005.

[50] E. Chikoidze, M. Boshta, M.H. Sayed, Y. Dumont, Large room temperature magnetoresistance of transparent Fe and Ni doped ZnO thin films, J. Appl. Phys. 113(4) (2013) 043713.

[51] S. Santra, A. De Luca, S. Bhaumik, Z. Ali, F. Udrea, J. Gardner, S.K. Ray, P.K. Guha, Dip pen nanolithography-deposited zinc oxide nanorods on a CMOS MEMS platform for ethanol sensing, RSC Advances 5 (2015) 47609-47616. 
[52] N. Hongsith, E. Wongrat, T. Kerdcharoen, S. Choopun, Sensor response formula for sensor based on $\mathrm{ZnO}$ nanostructures, Sens. Actuators, B 144(1) (2010) 67-72.

[53] Z. Ahmad, M.H. Sayyad, M. Yaseen, K.C. Aw, M. M-Tahir, M. Ali, Potential of 5, 10, 15, 20-Tetrakis (3',5'-di-tertbutylphenyl) porphyrinatocopper (II) for a multifunctional sensor, Sens. Actuators, B 155(1) (2011) 81-85.

[54] N.F. Hamedani, A.R. Mahjoub, A.A. Khodadadi, Y. Mortazavi, Microwave assisted fast synthesis of various $\mathrm{ZnO}$ morphologies for selective detection of $\mathrm{CO}, \mathrm{CH}_{4}$ and ethanol, Sens. Actuators, B 156(2) (2011) 737-742.

[55] A. Khayatian, M.A. Kashi, R. Azimirad, S. Safa, S.A. Akhtarian, Effect of annealing process in tuning of defects in $\mathrm{ZnO}$ nanorods and their application in UV photodetectors, Optik 127(11) (2016) 4675-4681.

[56] S.A. Studenikin, N. Golego, M. Cocivera, Fabrication of green and orange photoluminescent, undoped $\mathrm{ZnO}$ films using spray pyrolysis, J. Appl. Phys. 84(4) (1998) 22872294.

[57] A. Sawalha, M. Abu-Abdeen, A. Sedky, Electrical conductivity study in pure and doped ZnO ceramic system, Physica B. 404(8) (2009) 1316-1320.

[58] G.H. Kuo, H.P. Wang, H.H. Hsu, J. Wang, Y.M. Chiu, C.J. Jou, T.F. Hsu, F.L. Chen, Sensing of ethanol with nanosize Fe-ZnO thin films, J. Nanomaterials 2009 (2009) 4.

[59] B. Yuliarto, M. Igbal, Nugraha, Liquefied petroleum gas sensor based on Fe doped nanostructure zinc oxide thin film prepared by chemical bath deposition, J. Sains Materi Indonesia 2011 (2011). 
[60] M.V. Vaishampayan, R.G. Deshmukh, P. Walke, I.S. Mulla, Fe-doped $\mathrm{SnO}_{2}$ nanomaterial: a low temperature hydrogen sulfide gas sensor, Mater. Chem. Phys. 109(2) (2008) 230-234. 


\section{Figure Captions:}

Fig. 1. The AFM micrograph of $\mathrm{ZnO}$ seed layer (a) and the SEM images of the bare $\mathrm{ZnO}$ NRs (b) and 1.5 at.\% Fe doped- $\mathrm{ZnO} / \mathrm{ZnO}$ shell/core NRs (c).

Fig. 2. (a) $\mathrm{XRD}$ pattern of pure and Fe-doped $\mathrm{ZnO} / \mathrm{ZnO}$ shell/core nanorods (Inset: texture coefficient (TC) as a function of the Fe concentration. (b) The d-spacing value and grain size of the samples with various Fe concentration, along with patterns of (002) peaks in inset.

Fig. 3. The transmittance (a) and graph of $(\alpha h v)^{2}$ vs. photon energy (b) for Fe doped- $\mathrm{ZnO} / \mathrm{ZnO}$ shell/core NRs with different Fe concentrations as well as the value of the optical band gap in inset.

Fig. 4. The electrical resistivity of Fe doped- $\mathrm{ZnO} / \mathrm{ZnO}$ shell/core NRs (The inset: the I-V curves of samples).

Fig. 5. The response of the bare and doped $\mathrm{ZnO}$ NR samples to $500 \mathrm{ppm}$ ethanol vapor at different operating temperatures.

Fig. 6. The response curves of $\mathrm{x}$ at. $\%$ Fe doped- $\mathrm{ZnO} / \mathrm{ZnO}$ shell/core $\mathrm{NRs}(0 \leq \mathrm{x} \leq 9)$ to different concentrations of ethanol at the optimal operating temperatures.

Fig. 7. The electrical current (a) and normalized response curves (b) versus time of $\mathrm{x}$ at.\% $\mathrm{Fe}$ doped-ZnO/ZnO shell/core NR sensors $(0 \leq \mathrm{x} \leq 9)$ to $500 \mathrm{ppm}$ of ethanol vapor at the optimal operating temperatures. 


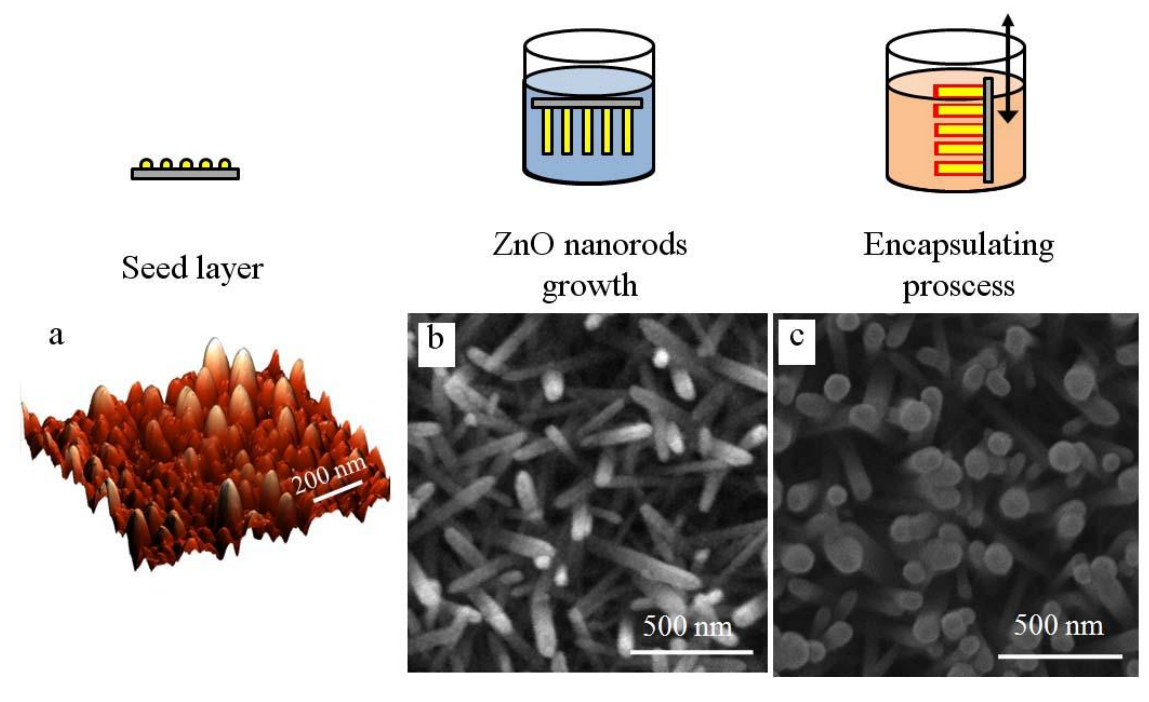

Fig. 1 

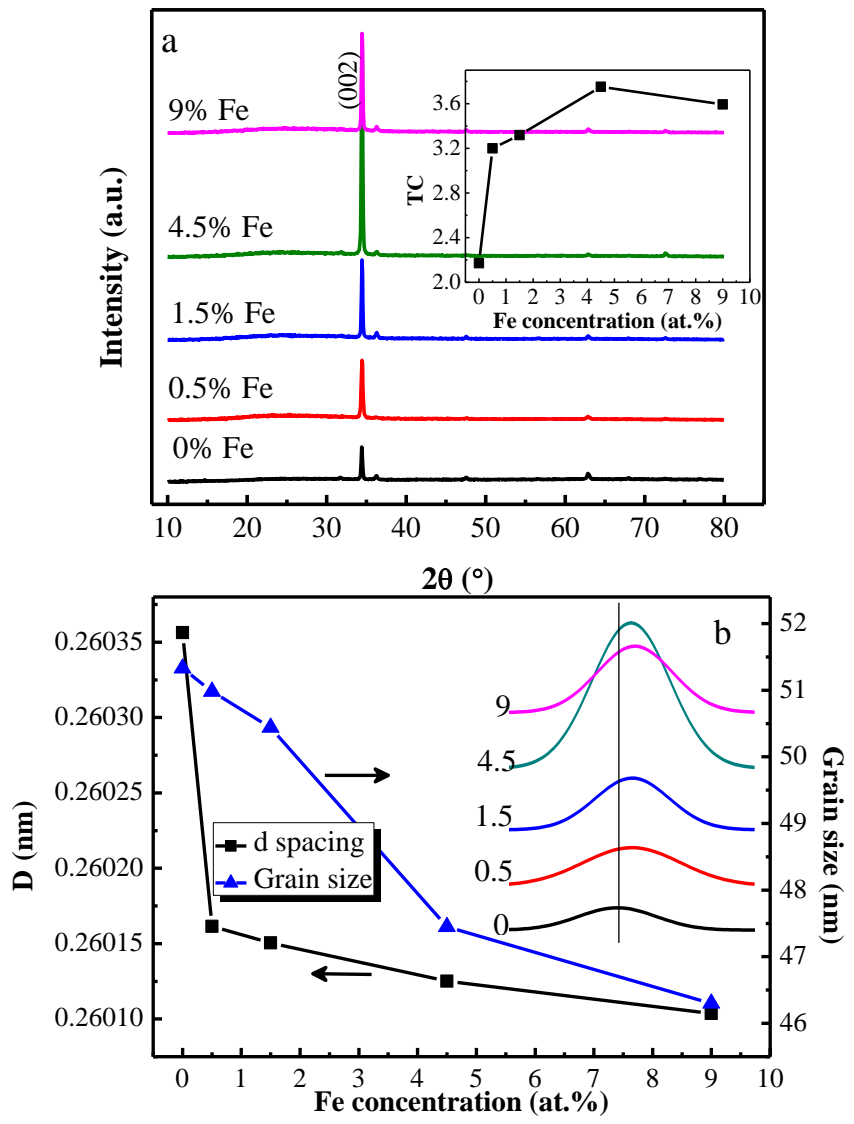

Fig. 2 

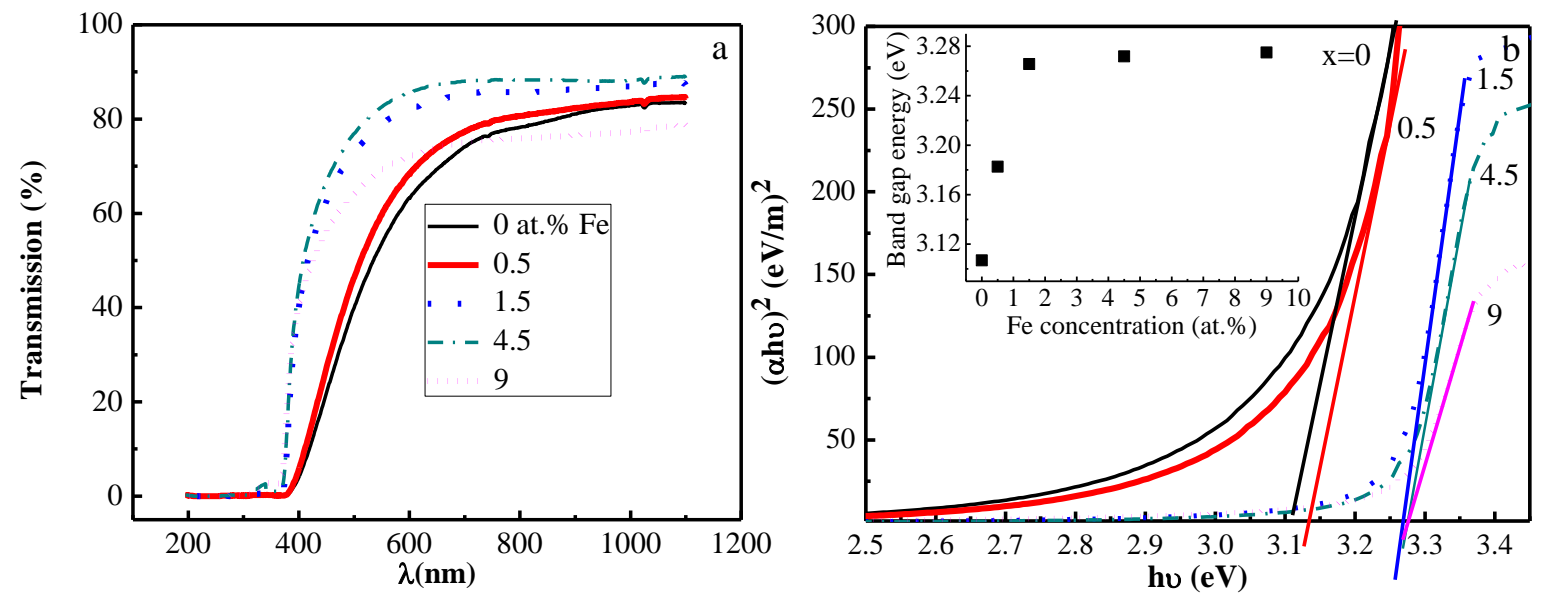

Fig. 3 


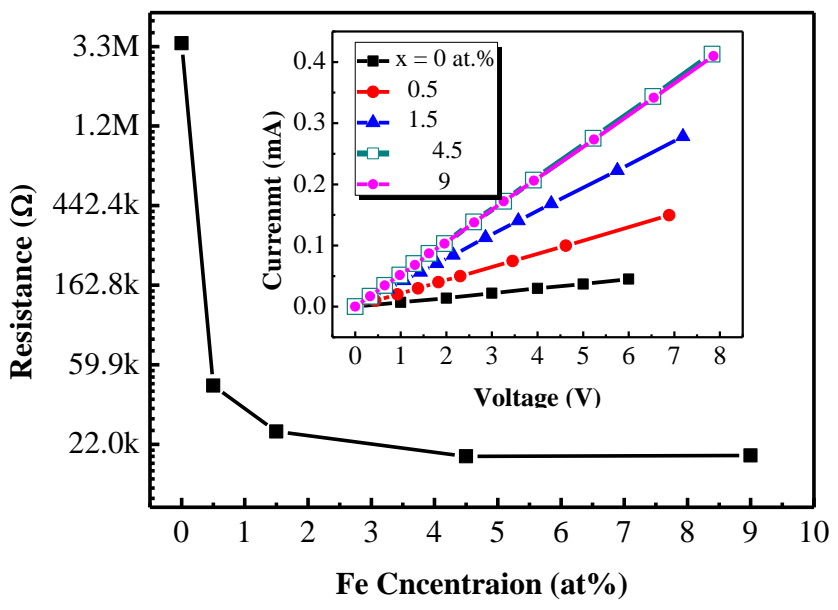

Fig. 4 


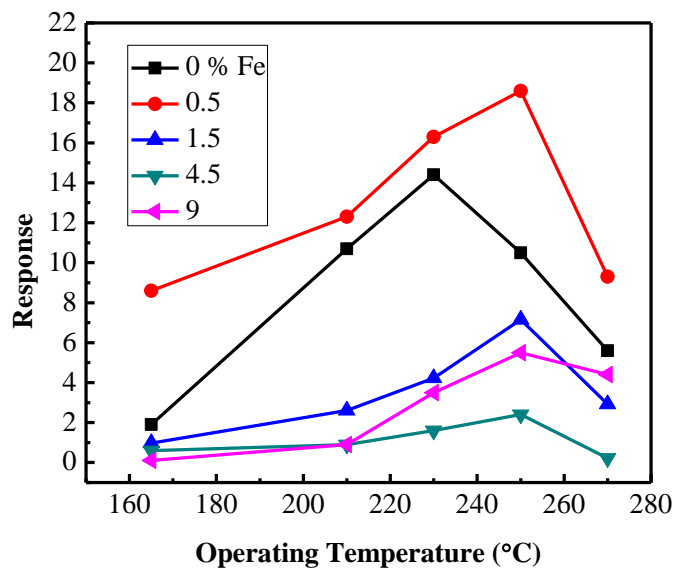

Fig . 5 

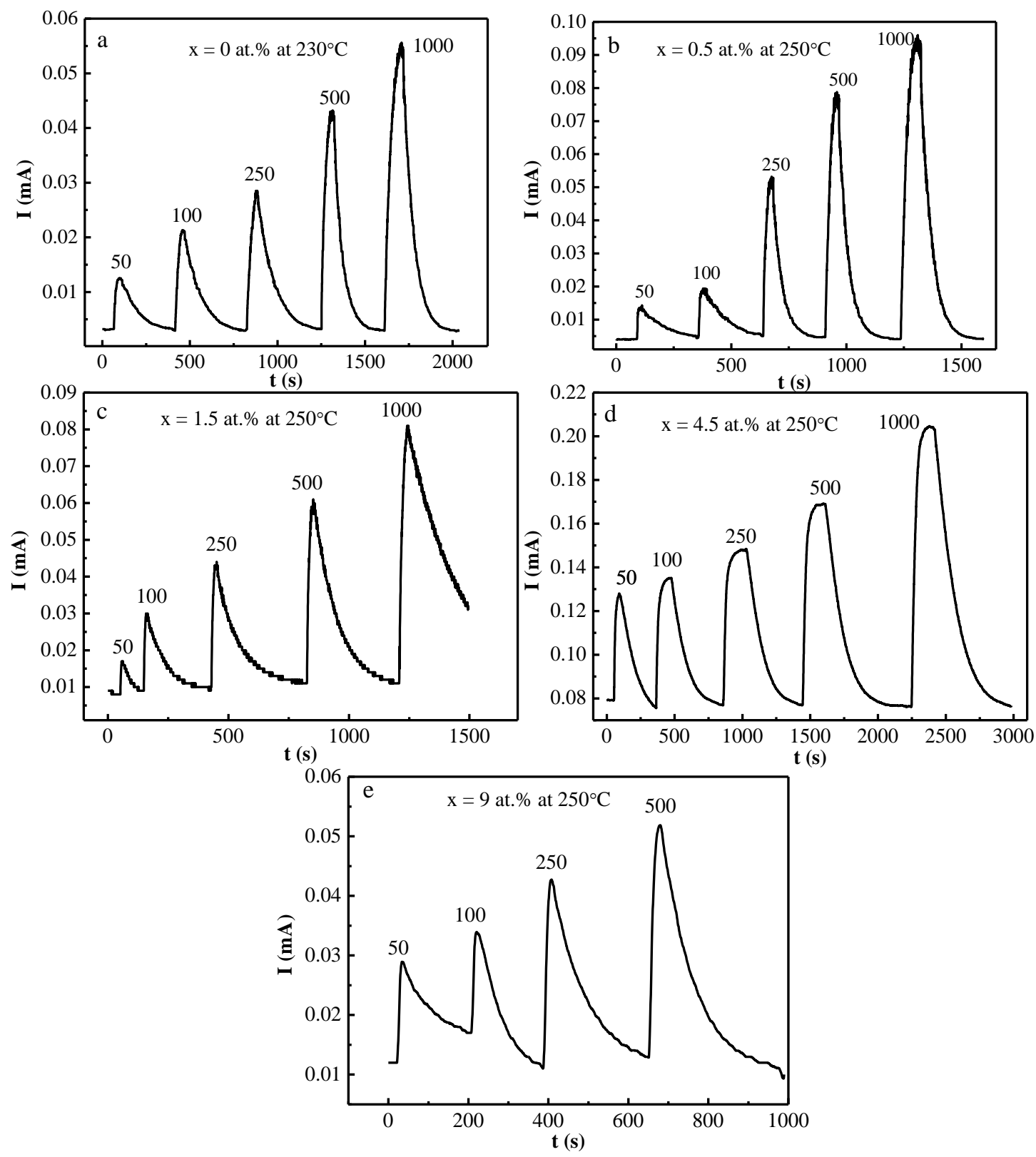

Fig. 6 

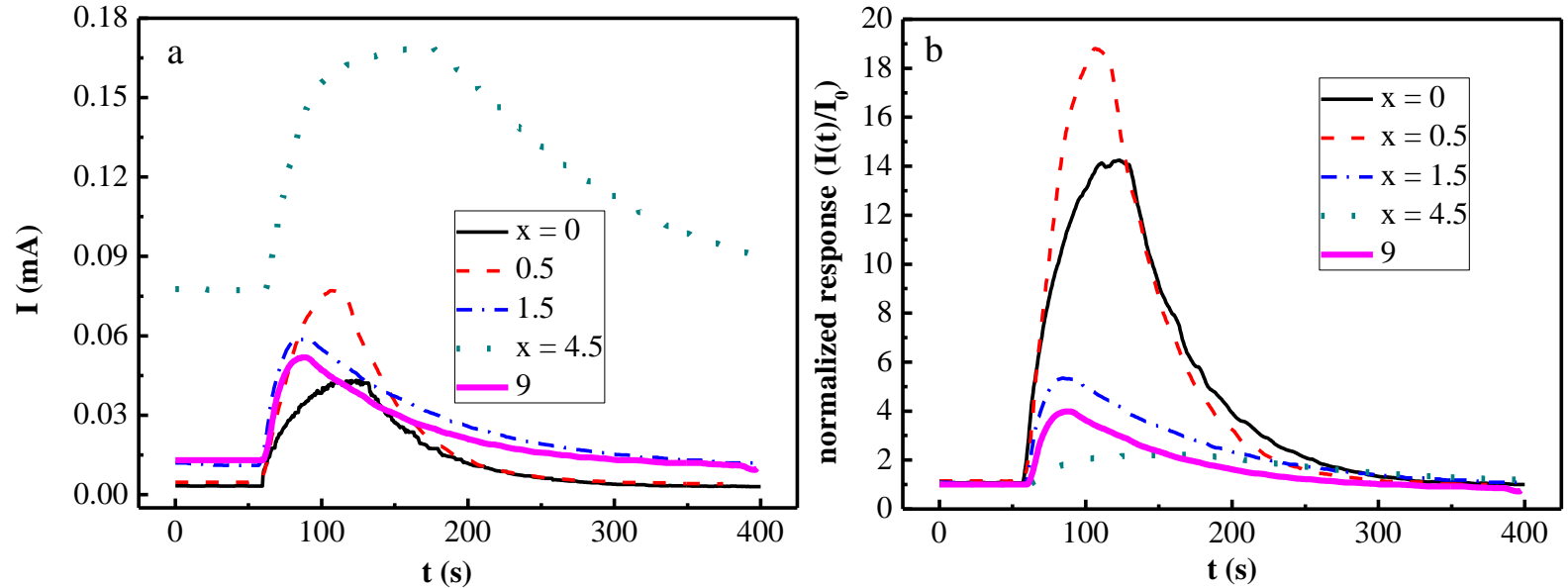

Fig. 7 